\title{
Transcriptome Analysis Reveals L-amino Acids as Olfactory Stimulant in the Large Yellow Croaker (Larimichthys crocea)
}

\author{
Awonfor Franklyn ${ }^{1,2,3}$, Yajun Wang ${ }^{1,2,3 *}$, Na Yu1,2,3, Jianbo Wang ${ }^{4}$, Qijun Le ${ }^{1,2,3}$, Xiaohuan Cao ${ }^{1,2,3}$ and Huakun Zheng ${ }^{1,2,3}$ \\ ${ }^{1}$ Key Laboratory of Applied Marine Biotechnology, Ningbo University, Ministry of Education, Ningbo, China \\ ${ }^{2}$ Marine Biotechnology Laboratory, School of Marine Sciences, Ningbo University, Ningbo, China \\ ${ }^{3}$ College of Science and Technology, Ningbo University, Ningbo, China \\ ${ }^{4}$ The National Fishery Technology Extension Center, Beijing, China
}

\begin{abstract}
Similar to bony fish, feeding preference in Larimichythys crocea is determined by the smell and taste of food which is mainly controlled by the olfactory system. Ten different L-types of amino acids at different concentration levels were introduced to the large yellow croaker and significant differences in the olfactory response with reference to odor detection were observed. Movement and feeding responds were taken within a 4-minutes interval which showed an increase in the responsiveness of the fish with increase in the concentration of specific amino acid from $0.01 \mathrm{M} / \mathrm{L}$ to $0.08 \mathrm{M} / \mathrm{L}$. There was a significant difference between different kinds of amino acid with high responses from L-Arginine and L- Tryptophan. The olfactory epithelium before and after administering L-amino acid was observed and it showed remarkable differences with the top of the cilia being inflated in the administered amino acid samples. RNA sequenced was done with Illumina HiSeq 2500 in which 40326272 and 35794904 clean reads from two amino acids namely L- Arginine and L-Tryptophan were acquired respectively and more than $845 \%$ of the read were mapped to the reference genome. Comparing the gene expression of two L-types amino acid, 16701 unigenes were significantly differentially expressed including 10142 up-regulated and 6503 down-regulated genes. 100 olfactory receptor genes were detected, these genes include; Olfactory receptors (OR), Vomeronasal receptors (VR) and Trace-Amine Associated Receptors (TAAR) with low levels of Olfactomedin like Protien (OLFM) genes. OR expressed genes were then selected for further quantitative RT-PCR analysis. With the use of Gene Ontology (GO) and Kyoto Encyclopedia of Genes and Genomes (KEGG) analyses of the differential expressed genes were found out that multiple genes were involve in olfactory activities such as signaling, single organism signaling, cell communication and olfactory transduction. These transcriptome analyses provide clear information on olfactory related genes expression of Larimichthys crocea with respect to L-type amino acids. Also, this study help us identify which L-type amino acid is a potent phagostimulant to the fish and how it can be employed in the fish feed thereby increasing the protein intake of the fish.
\end{abstract}

Keywords: Amino acid; Large yellow croaker; Larimichthys crocea; Olfactory receptor genes; Transcriptome; Behavior; Feeding

\section{Introduction}

Fish perceived small molecules with high aqueous solubility by chemoreception. The chemical senses of fish can be divided into olfaction, gustation and less well defined sense which is represented by the general chemical senses and the existing chemosensory cells $[1,2]$. Fish olfactory sense can detect four main classes of chemicals (odorants) mainly; amino acids, gonadal steroids, bile acids and prostaglandins. Amino acid is a kind of compound that is highly effective chemosensory stimuli in fish. Behavioral evidence has shown that amino acids are detected by a variety of fish [3] and electrophysiological experiments have proven that amino acids are highly effective stimuli in both olfactory and gustatory systems [4]. Three types of olfactory related receptor have been reported in the olfactory epithelium of fish; they include; Olfactory receptors (OR), Vomeronasal Receptor (VR) and Trace-Amine Associated Receptors (TAAR) $[5,6]$ OR genes are a type of G-protein coupled receptors and they are being expressed in the ciliated sensory neurons.

The Olfactory receptors (OR) genes have been divided into two sub classes (class I and Class II) based on their functions. The OR of fish belongs to the sub class I because the receptors of this subclass recognize water-soluble odorants which the fish exhibits [7]. Vomeronasal Receptor (VR) genes are located in the microvillus of the sensory neuron of the olfactory epithelium. It is broken down to two sub groups. V1Rs and V2Rs. VRs are the main pheromones receptors. $\mathrm{V} 1 \mathrm{R}$ and V2R receptor genes are called ORA (olfactory receptors related genes to class A) and OlfC (olfactory receptors related to class C). There is a total of six types of ORA found in fish which include ORA 1-6. OlfC receptor mainly recognizes water-solute and it changes to ORA in vertebrate when they transition from water to land. TraceAmine Associated Receptors (TAAR) gene family is mostly found in zebra fish, and Danio rerio [8]. The TAAR gene is divided into three types. The aim of investigation was to determine if L-type amino acid is a potent olfactory stimulus in the large yellow croaker, the related gene expression of the olfactory system and the olfactory gene transcriptome analysis.

These findings clearly demonstrate that the expression of VR, $\mathrm{OR}$ and TAAR genes are induced by L-amino acid in different degrees. 3 types of olfactory receptors are being involved in scenting the external smell substances, the perception of different gene odors results in differentially expressed genes. OR receptor is the major odor

*Corresponding author: Dr. Yanjun Wang, Marine Biotechnology Laboratory, School of Marine Sciences, Ningbo University, Ningbo, China, 315211, Tel: +86574-87600170; Fax: +86-574-87609581; E-mail: wangyajun@nbu.edu.cn

Received April 14, 2017; Accepted April 24, 2017; Published April 26, 2017

Citation: Franklyn A, Wang Y, Yu N, Wang J, Le Q, et al. (2017) Transcriptome Analysis Reveals L-amino Acids as Olfactory Stimulant in the Large Yellow Croaker (Larimichthys crocea). J Aquac Res Development 8: 475. doi: 10.4172/21559546.1000475

Copyright: (c) 2017 Franklyn A, et al. This is an open-access article distributed under the terms of the Creative Commons Attribution License, which permits unrestricted use, distribution, and reproduction in any medium, provided the original author and source are credited. 
perception gene family. The expression of VR genes is directly related to the growth and development of the individual. The smell receptor signaling pathway is directly related to the growth and development of the individual. The smell receptor signaling pathway of large yellow croaker have some attached proteins, OLFM gene functions in the support and implementation of olfactory function and these functions may also be involved in the signaling pathway.

\section{Materials and Methods}

\section{Experimental animal and reagents}

2,500 large yellow croaker (Larimichthys crocea) with approximate mean weight of $7-15 \mathrm{~g}$ and length $8-10 \mathrm{~cm}$ were captured in the sea and cultured in 10 hexagonal cement ponds of $1 \mathrm{~cm}^{3}$ volume (Figure 1) and filled with fresh sea water with 250 fish per pond were cultured in Xiangshan Bay, Ningbo-China. The fish were breed with normal fish feed of $2 \mathrm{~mm}$ size in diameter three times daily for 2 months as they were still juveniles. This was also to enable the fish to adapt to its new environment before the experiment.

\section{Experimental method}

Anatomy and microscopic studies of the olfactory organ: Large yellow croaker (Larimichthys crocea) was anesthetize with MS-22 anesthetic. the position, shape and quantity of the nostril was observed, the skin was gently cut open with the use of a scissors. Forceps was use to remove the neurocranium and the olfactory cartilage. The skin around the nostril was also removed thereby exposing the olfactory

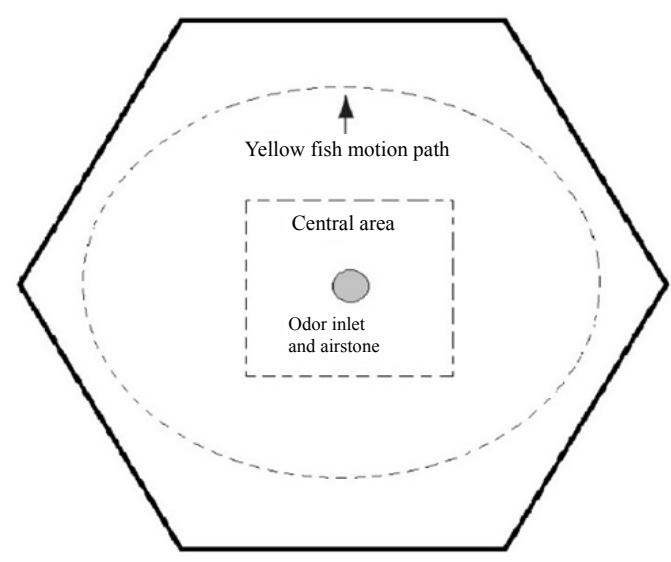

Figure 1: The experimental pond.

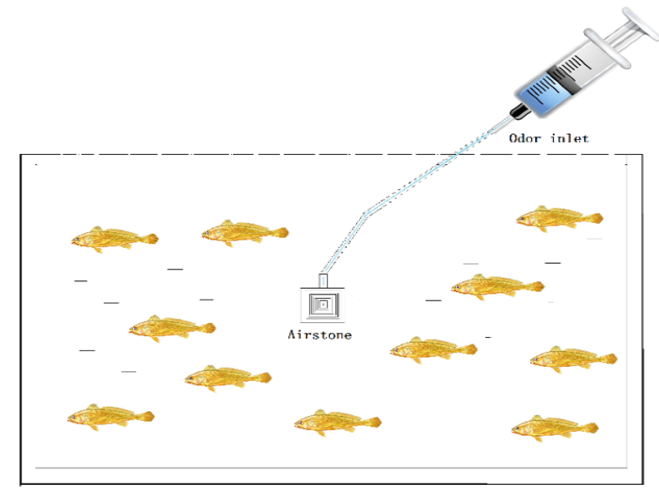

Figure 2: Experimental setup. sac. The olfactory sac was then collected with the use of forceps. The olfactory organ was preserved in the refrigerator at $4^{\circ} \mathrm{C}$. It was washed with PBS buffer and fixed in 3\% glutaraldehyde solution for 2 hours. It was later rinsed twice with $0.1 \mathrm{M} / \mathrm{L}$ PBS buffer with a 15 -minute rinse time period.

Dehydration of the olfactory organ was done by soaking it in a $30 \%, 50 \%, 70,80 \%, 90 \%$ ethanol respectively for 10 to 15 minutes. The samples were preserved in a small amount of Tert-butanol and stored in a refrigerator at $20^{\circ} \mathrm{C}$. The frozen samples were removed, dried with a vacuum freeze-drying machine and gold sprayed. It was then filmed under a scanning electron microscope.

Amino acid concentration selection: During the experiment, the temperature of the water was kept at $20-22^{\circ} \mathrm{C} .10$ different amino acids with concentrations of $0.01 \mathrm{M} / \mathrm{L}, 0.02 \mathrm{M} / \mathrm{L}, 0.03 \mathrm{M} / \mathrm{L}, 0.04 \mathrm{M} / \mathrm{L}, 0.06$ $\mathrm{M} / \mathrm{L}, 0.08 \mathrm{M} / \mathrm{L} .20 \mathrm{ml}$ of each amino acid concentration was injected into the various ponds through the air stone at the center of the pond with the help of a syringe (Figure 2). Two-minute observation time to get the concentration with the highest response rate for the next stage. The water was changed after sample was tested.

Response under five selected amino acid: The second stage of the experiment, $0.08 \mathrm{M} / \mathrm{L}$ concentration with 5 different $\mathrm{L}$-amino acid with high responsive rate were used. $20 \mathrm{ml}$ dissolved amino acid of $0.08 \mathrm{M} / \mathrm{L}$ was injected slowly with the use of a syringe through the air stone. This was done at three different intervals ( $7 \mathrm{am}, 12 \mathrm{pm}$, and $5 \mathrm{pm})$. At $5 \mathrm{pm}$, five-minute observation and recording was then taken with the aid of a camera with a 1 minute set interval before recording for complete dilution of the amino acid. The water was changed after sample was tested.

The response of the fish was classified into two variables;

- Movement response which is the number of times the fish swam towards the air stone.

- Feeding response which is the number of times the fish open their mouth in water in response to food (snapping) or bites on the air stone.

Fish response was analyzing by one way ANOVA with SPSS Amino acids with high responsive rates were used for the next stage of this experiment.

RNA Sequence analysis: The final stage of the experiment which was transcriptome analysis, two amino acids namely L-Tryptophan and L-Arginine was used as these two were more responsive than the other amino acids. The samples were taken at the end of the recording.

\section{Sample collection and RNA isolation}

After observation and video recordings, ten fish were collected from each pond. The olfactory epithelium was carefully dissected with the use of forceps and scissors and preserved in liquid nitrogen. RNA extraction was done with TRIZOL reagent (Invitrogen). The quality and purity of the RNA was checked by $1 \%$ agarose gel and NanoDrop ND1000 Spectrophotometer (NanoDrop Technologies Inc, Wilmington, DE, USA) respectively. And the RNA integrity was assessed by the use of the RNA Nano 6000 Assay Kit (Agilent Tech, CA, USA).

\section{cDNA library construction and sequencing}

mRNA was isolated and enriched from the high-quality RNA by oligo (dt) magnetic beads (Illumina, CA, USA) and fragmentation. The fragmented mRNA was then converted to cDNA by reverse transcription. Short fragments were then purified with QLAQuick 1PCR extraction kit (QIAGEN, Germany) and eluted with $10 \mu \mathrm{L}$ EB 
Citation: Franklyn A, Wang Y, Yu N, Wang J, Le Q, et al. (2017) Transcriptome Analysis Reveals L-amino Acids as Olfactory Stimulant in the Large Yellow Croaker (Larimichthys crocea). J Aquac Res Development 8: 475. doi: 10.4172/2155-9546.1000475

Page 3 of 9

\begin{tabular}{|c|c|c|}
\hline Gene ID & Primer sequence $\left(5^{\prime} \rightarrow 3^{\prime}\right)$ & Gene description \\
\hline gi|734606196| & $\begin{array}{l}\text { F: TTCAATGGGAGGCATAGCTG } \\
\text { R: CTGGGAAACGGTGCAAGAT }\end{array}$ & Olfactory receptor $52 \mathrm{~N} 4$ \\
\hline gi|734628121| & $\begin{array}{l}\text { F: AGCTTTCACCCGACTATCT } \\
\text { R: TGTTTAGACTCGCCTGTAATG }\end{array}$ & Olfactory receptor $10 \mathrm{C} 1$ \\
\hline gi|734643370| & $\begin{array}{l}\text { F: CTATGCCAGCACTCTCTTTC } \\
\text { R: ACAAGGTGGAGGTGAGAA }\end{array}$ & Olfactory receptor 2D3 \\
\hline gi|734650358| & $\begin{array}{l}\text { F: CTTTTCAGCACGACCATCTACC } \\
\text { R: GACATGGCTGCCAACAGTAAG }\end{array}$ & Olfactory receptor 2D3 \\
\hline gi|734650356| & $\begin{array}{l}\text { F: CGCCGCGAGTGTCCACTAAT } \\
\text { R: TTGGCTTGTGCCTGCTTG }\end{array}$ & Olfactory receptor $13 \mathrm{C} 2$ \\
\hline gi|734650447| & $\begin{array}{l}\text { F: GAGTGCATAGTCGACAAGAG } \\
\text { R: CCTATGTTGGTGTGATGGTAG }\end{array}$ & Olfactory receptor $4 \mathrm{C} 11$ \\
\hline gi|734649665| & $\begin{array}{l}\text { F: AGTAGCCACAGTTCAAGAAGAC } \\
\text { R: TGGGTTCAACATGGGAGGA }\end{array}$ & Olfactory receptor $2 \mathrm{~A} 12$ \\
\hline gi|734643368| & $\begin{array}{l}\text { F: TGGCATGGTGTCTATAGGT } \\
\text { R: GAGCAGTGTCTGCAAAGAG }\end{array}$ & Olfactory receptor 1361 \\
\hline
\end{tabular}

Table 1: Primers for RT-qPCR analysis.

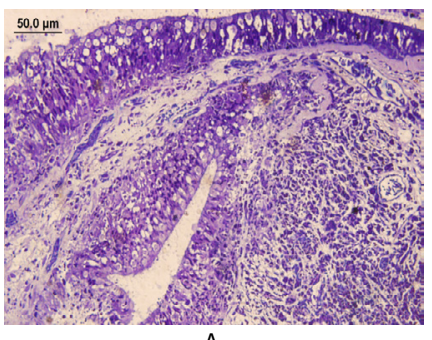

A

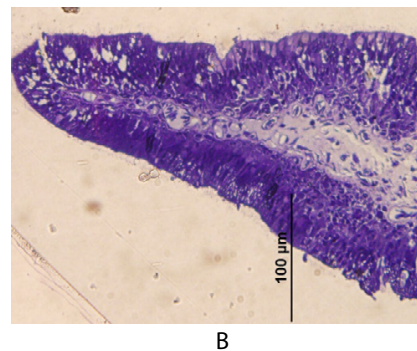

B

Figure 3: Optical microscopic observation before the introduction of L-amino acid showing well arranged, oval, circular distributed nerve cells.

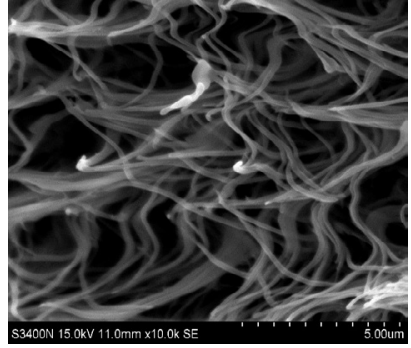

A

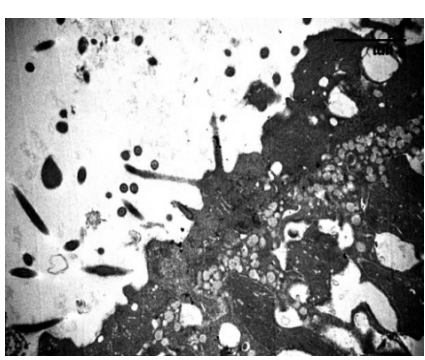

$\mathrm{B}$
Figure 4: (4A) TEM picture of the Cilia (4B) SEM picture after I-amino acid Transmission electron and Scanning Electron microscopic study of the never cells picture after the introduction of L-amino acid.

buffer. cDNA libraries were then sequenced with Illumina HiSeq 2500 (Novogene, Beijing). The Illumina data were then transformed into sequence data by base calling using CASAVA software. Clean reads were obtained from the raw reads by the following process;

- Removal of sequence through identifying the reads that contained adaptor contamination,

- Low quality reads.

- Reads that contained more than 5\% unknown nucleotides.

The data was compared with the reference genome of large yellow croaker by the use of TopHat software. The unigenes were BLASTXsearched against the National Center for Biotechnology information (NCBI) non-redundant protein sequence (NR) database, the NCBI non-redundant nucleotide sequence (NT) database, KEGG orthologue database and Swissprot and the PFAM with and E-value threshold of $10^{-5}$

\section{Differentially expressed genes identification and analysis}

RPKM (Fragments per Kilo base per Million) technique was use to eliminate different gene expression levels. Differentially expressed genes were identified through the use of rigorous algorithm developed by BGI. Significantly differential gene expression was set as $\mid \log _{2}$ Ratio $\mid \geq 1$ and $\mathrm{q}<0.05$. Gene analysis was done through an international standardized gene functional classification system (Gene Ontology (Go)). This system was used to describe three main components which are; cellular components, molecular functions and biological processes. We use the KEGG (Kyoto Encyclopedia of Genes and Genomes) database to assign and predict putative functions and pathways associated with the assembled sequence and gene ontology annotations and pathways analysis for differential gens was obtained using the Blast2GO program and KEGG database (version 3.0) ( https://www.blast2go.com/)

\section{Analysis of RT-qPCR}

Ten differentially expressed genes from two highly responsive amino acid namely L-Arginine and L-Tryptophan were selected for RT-qPCR analysis. Primers for this analysis were designed by the use of Primer 5 software (Premier Biosoft international) (Table 1). For an internal control, $\beta$-actin gene was use. RNA reverse-transcription to cDNA was done using Prime Script TM RT reagent Kit (Takara, Japan). Real time PCR reaction volume composed of $2 \mu \mathrm{l}$ cDNA, $0.5 \mu \mathrm{l}$ forward primer, $0.5 \mu$ reverse primer, $10 \mu$ SYBG Green (Roche, USA and $6 \mu \mathrm{l}$ water. Amplification of PCR reaction was performed under the following conditions: $50^{\circ} \mathrm{C}$ for $2 \mathrm{~min}$ and $95^{\circ} \mathrm{C}$ for $2 \mathrm{~min}$, followed by 40 cycles of $95^{\circ} \mathrm{C}$ for $15 \mathrm{~s}$ and $60^{\circ} \mathrm{C}$ for $30 \mathrm{~s}$.

\section{Results}

\section{Observation of the olfactory tissue before and after the intro- duction of L-amino acid}

Olfactory tissue before introduction of L-amino acid: Before the introduction of L-amino acid, Optical microscopic observation shows that the olfactory cells in the olfactory panel are arranged neatly under the absence of food odor. Three types of olfactory nerve cells were noticed; the cilia, micro-villi and sensory cells. These cells were well arranged, oval, circular and were distributed on the upper layer of the olfactory epithelium (Figures 3A and 3B). Cilia cells were evenly distributed and they all have same size.

Olfactory tissue after the introduction of $\mathrm{L}$-amino acid: After the introduction of L-amino acid, optical microscopic observation shows 
Citation: Franklyn A, Wang Y, Yu N, Wang J, Le Q, et al. (2017) Transcriptome Analysis Reveals L-amino Acids as Olfactory Stimulant in the Large Yellow Croaker (Larimichthys crocea). J Aquac Res Development 8: 475. doi: 10.4172/2155-9546.1000475

Page 4 of 9

\begin{tabular}{|c|c|c|c|c|c|c|c|c|c|c|}
\hline $\begin{array}{l}\text { Amino acid } \\
\text { concentration }\end{array}$ & Arginine & Tryptophan & Methionine & Valine & Leucine & Histidine & Lysine & Threonine & Alanine & Isoleucine \\
\hline $0.01 \mathrm{M} / \mathrm{L}$ & - & - & - & - & - & - & - & - & - & - \\
\hline $0.02 \mathrm{M} / \mathrm{L}$ & * & * & * & & - & - & - & - & - & - \\
\hline $0.04 \mathrm{M} / \mathrm{L}$ & ** & ** & * & * & * & * & - & - & - & - \\
\hline $0.06 \mathrm{M} / \mathrm{L}$ & $* * *$ & $\star \star * *$ & ** & $* *$ & $\star *$ & $* *$ & * & * & * & - \\
\hline $0.08 \mathrm{M} / \mathrm{L}$ & $\star * \star * *$ & $* \star \star *$ & ** & ** & ** & $* *$ & ** & ** & * & - \\
\hline \multicolumn{2}{|l|}{ Levels } & - & \multicolumn{2}{|c|}{ * } & \multicolumn{2}{|r|}{ ** } & \multicolumn{2}{|r|}{$* * *$} & \multicolumn{2}{|c|}{$\star * \star *$} \\
\hline \multicolumn{2}{|l|}{ Response rate } & No response & \multicolumn{2}{|c|}{ Low response } & \multicolumn{2}{|c|}{ Moderate response } & \multicolumn{2}{|c|}{ High response } & \multicolumn{2}{|c|}{ Highest response } \\
\hline
\end{tabular}

Table 2: The concentration gradient of ten L-amino acid.

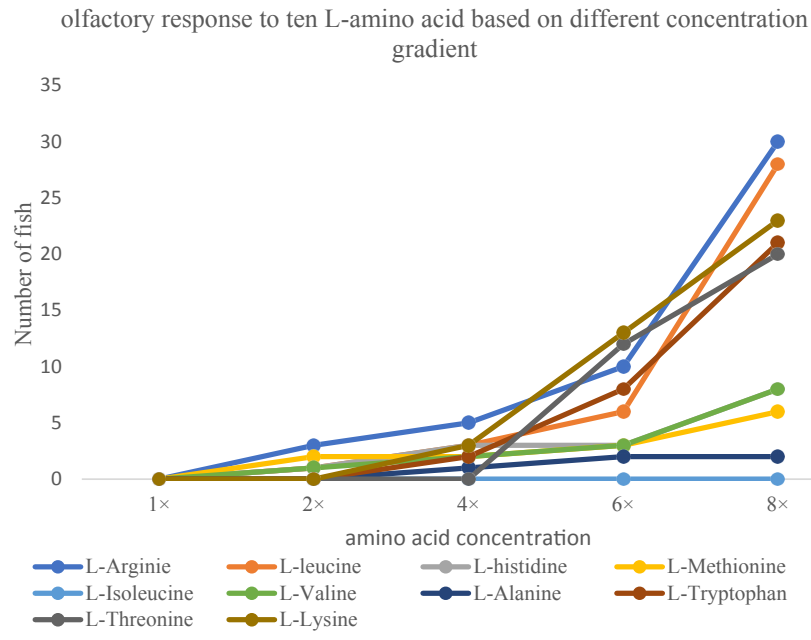

Figure 5: Olfactory response to ten different amino acids based on different concentration gradient.

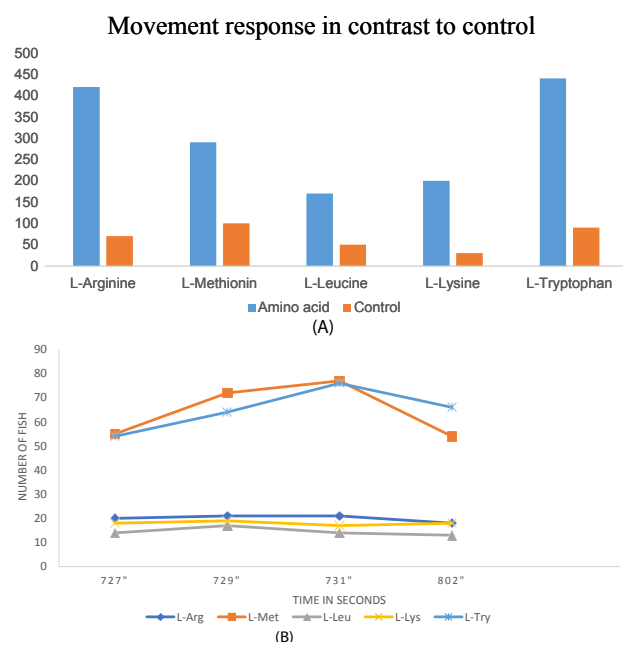

Figure 6: (6A) Movement response to five different amino acids with contrast to normal feed. (6B) Time gradient for movement response.

that all the nerve cells (the cilia, micro-villi and sensory cells) at the first layer of the olfactory epithelium were closely arranged than before the input of L-amino acid, the oval nerve cells have moved upwards. The structure and number of mitochondria in the internal medullary cell layer increased remarkable. The apex of the cilia was inflated into a globular structure (Figures $4 \mathrm{~A}$ and $4 \mathrm{~B}$ ) Changes in the volume of the cilia causes the diameter of the swollen apex to increases to $1 \mathrm{um}$. There was a tendency of continues swellings as more L-amino acid is introduced.

\section{Olfactory behavioral response}

Amino acid response: Feeding behavior is stimulated by amino acid $[9,10]$. The stimulation of the olfactory receptors (OR) by food is a dual process;

- Firstly, sensory information from the water molecules are analyzed by the olfactory nervous system in the olfactory epithelium [11].

- Next, natural fish behavior such as feeding, predator avoidance and mating are then enhanced.

These two phases then screen out the ten different amino acids. Five different concentrations of amino acid were prepared and tested, the responsiveness of the fish was recorded.

Based on the ten L-amino acid concentration gradients above taken after 2 minutes, L-isoleucine concentrations had no influence on the olfactory system of the fish. All L-amino acid with $0.01 \mathrm{M} / \mathrm{L}$ concentrations do not stimulate the system (Table 2) There was an increase in response rate with increase in concentration as the fish moved faster towards the air stone with the highest response rate from L-Arginine, L-Methionine, L-Leucine, L-Tryptophan and L-Lysine at $0.08 \mathrm{M} / \mathrm{L}$ concentration (Figure 5).

With these results, the next round of experiments was set with $8 x$ $(0.08 \mathrm{M} / \mathrm{L})$ concentration with the following L-amino acids; L-Arginine, L-Leucine, L-Methionine -Lysine and L-Tryptophan.

Movement response: This was determined by the number of times the fish swam towards the air stone when dissolved L-amino acids was injected. We used the five amino acids with $0.08 \mathrm{M} / \mathrm{L}$ concentration (which shows high responsiveness in the previous experiment) in contrast to normal feed. The highest response rates were L-Tryptophan with $443 / 4$ minutes' fish response rate followed by L-Methionine with 435/4 minutes while the lowest was L-Leucine with $185 / 4$ minutes (Figures 6A and 6B). With the use of One way ANOVA testing $\mathrm{P}<0.05$, there was significant difference between the control and the different amino acids. Also between different amino acids.

Feeding response: Feeding response was determined by the number of times the fish bite the air stone after dissolved amino acid was injected. With feeding response, the most responsive amino acid was L-Tryptophan with a response rate of $122 / 4$ minutes followed by L-Methionine with 82/4 minutes and L- Arginine with 51/4 minutes (Figures 7A and 7B). With One-way ANOVA testing, $\mathrm{P}<0.05$, there was a remarkable significant difference in the response of the different amino acids.

Based on the findings above, there was an average response rate within one minute after the amino acid was introduced into the various ponds this is due to dilution of the amino acid. Feeding response 
gradually increases at a faster rate with L-Tryptophan within 3 minutes and 12 seconds of the 5 minutes' experimental time. Which indicated that they can completely consumed the food with L-Tryptophan in a period of 3 minutes 12 seconds. While the other L-amino acids had slower response (Figure 8).

\section{Illuming sequencing}

Using illunima paired-end sequence techniques (HiSeq 2500) for a single compound, the total raw data of L-Tryptophan and L-Arginine, control reads 35794904-40326272. After quality control and data cleaning with the removal of duplicate sequences and low-quality reads, almost $18 \%$ of the data was filtered out. Raw $Q$ base rate of nearly 94\% (Figure 9).

\section{Gene distribution and comparison rate analysis}

This was done by the use of TopHat softwear [12] on a single compound. Each sample sequence was filtered with the reference genome so as for it to fit into the genome. In comparison, the experimental groups rates are usually higher than $80 \%$. Gene sequence distribution was based on the species gene annotation in the file database (Table 3). Genetic statistics comprises of three functional components (Exon, Intron and intergenic). Currently, the large yellow croaker has a complete genome sequence.

Sample distribution is not much affected as the differentially

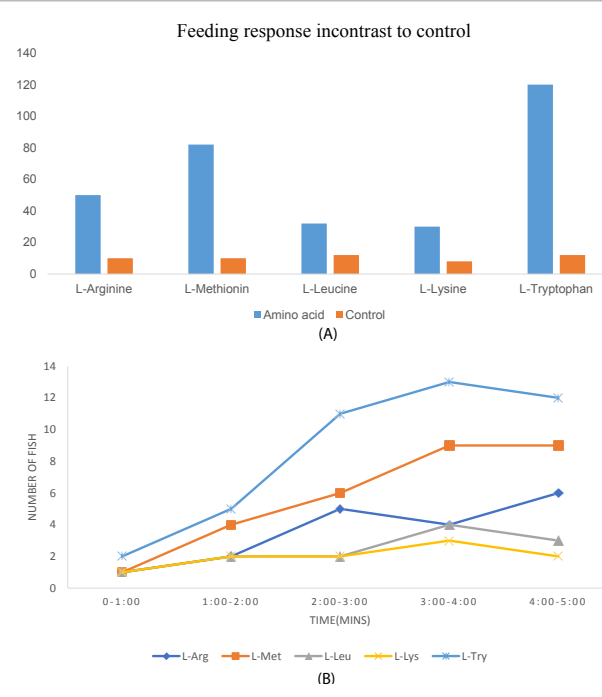

Figure 7: (7A) Feeding response to five different amino acids in contrasts to normal feed. (7B) Time gradient for feeding response.

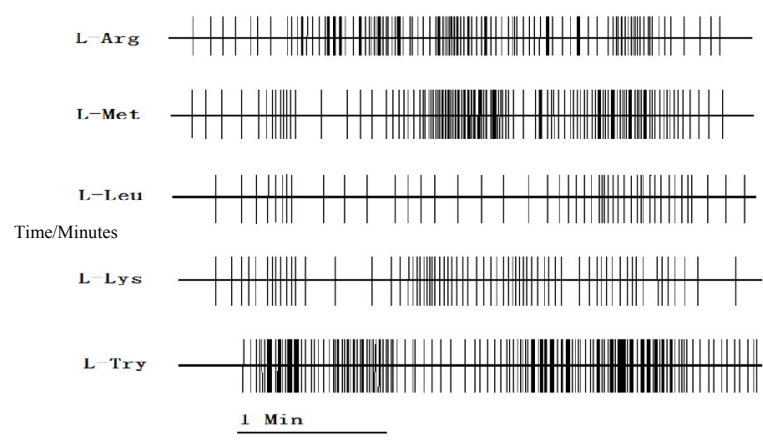

Figure 8: Four minutes' response rate of 5 different amino acids.

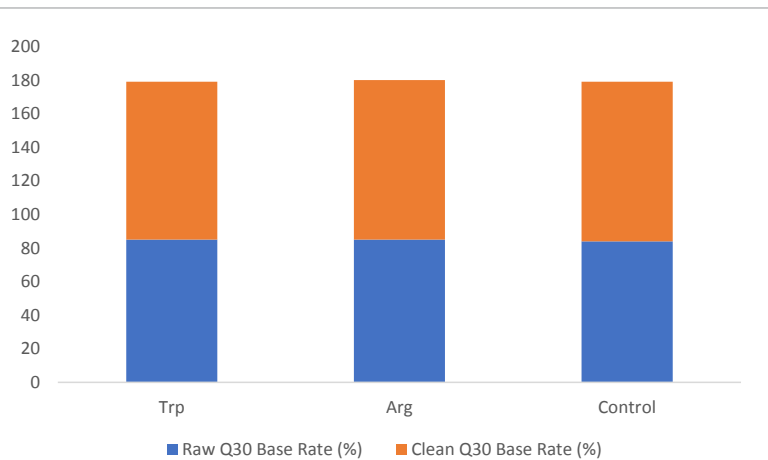

Figure 9: Raw Q30 base rates (\%) and Q30 bases rates (\%) distribution analysis.

\begin{tabular}{|c|c|c|c|}
\hline \#library & L-Tryptophan & L-Arginine & Control \\
\hline Total Reads & $32,159,790$ & $29,503,948$ & $32,272,020$ \\
\hline Mapped Reads & $25,832,698$ & $23,875,378$ & $25,684,902$ \\
\hline Mapping Rate & 0.8 & 0.81 & 0.8 \\
\hline Unmapped Reads & $6,327,092$ & $5,628,570$ & $6,587,118$ \\
\hline Multi_map Reads & $1,090,489$ & 846,329 & $1,048,015$ \\
\hline Multi_map Rate & 0.03 & 0.03 & 0.03 \\
\hline
\end{tabular}

Table 3: Data of reads.

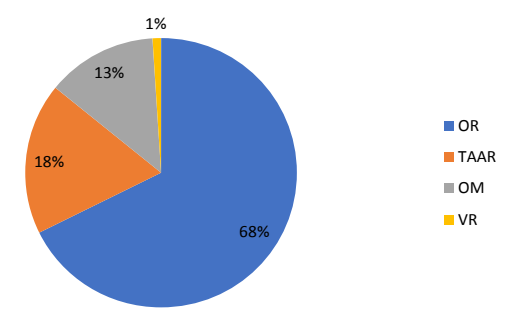

Figure 10: Percentage composition of all olfactory related genes.

expressed genes account for only a small portion. All the sample should therefore have a similar distribution expression based on the gene expression levels of all the samples. Gene expression density can be obtained from the picture below. We can see a low distribution of data; control group is at its lowest. From the picture, it can be deduced that several odors have effects on the gene transcription of the large yellow croaker.

\section{Differential expression analysis}

A total of 16701 differentially genes expressed genes were detected and it include 10142 up regulated genes and 6503 down regulated genes. 62 Olfactory receptor genes (OR) were detected and it comprises of 54 up regulated genes and only 6 down regulated genes. 1 Vomeronsal receptor gene (VR) was identified. 17 Trace Amine-associated receptor genes (TAAR) were identified. 12 Olfactomedin like protein (OM) were also identified (Figure 10).

RPKM (Reads per kilobase Milion mapped reads) was used to calculate the expression level of differentially expressed genes. A ratio of $\mid \log _{2}$ Ratio $\mid \geq 1$ and $\mathrm{q}<0.05$ as a differentially expressed gene was used. Up and Down sequence expresses different number of genes.

From (Figure 11) of differential expression genes, the orange spots represent up-regulated genes while green spots indicate down-regulated genes. The grey spots represent genes that did not show any obvious change between the control and both L-Arginine and L-Tryptophan. It 

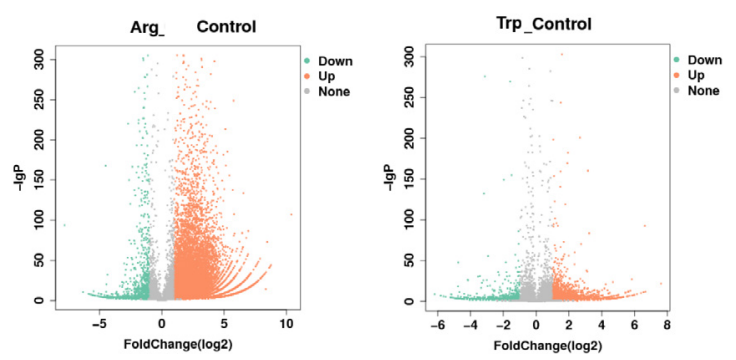

Figure 11: Genes differential expression under L-Arginine and L-Tryptophan.

\begin{tabular}{|c|cc|c|}
\hline Gene ID & Log $_{2}$ Fold Change & Padj-value & Gene description \\
\hline gi|734604709 & 1.620816144 & $8.4 \mathrm{E}-70$ & Olfactory marker protein \\
\hline gi|734648984 & 3.051823117 & $4.2 \mathrm{E}-42$ & Olfactory receptor 49 \\
\hline gi|734650735 & 3.098365703 & $4.65 \mathrm{E}-29$ & Olfactory receptor 52J3 \\
\hline gi|734649781 & 2.145293795 & $2.79 \mathrm{E}-20$ & Olfactory receptor 11A1 \\
\hline gi|734648879 & 1.244386638 & $1.55 \mathrm{E}-20$ & Olfactomedin-4 \\
\hline gi|734648986 & 1.355013231 & $3.53 \mathrm{E}-19$ & Olfactory receptor 13C2 \\
\hline gi|548377690 & 5.11826526 & $2.75 \mathrm{E}-18$ & Olfactomedin-like protein 2A \\
\hline gi|734631861 & 1.538494183 & $1.85 \mathrm{E}-18$ & Olfactory receptor 5B17 \\
\hline gi|734648883 & 1.093615303 & $7.43 \mathrm{E}-18$ & Olfactomedin-4 \\
\hline gi|554882886 & 2.612938875 & $1.03 \mathrm{E}-14$ & Olfactory receptor 49 \\
\hline gi|548536498 & 2.98733439 & $3.63 \mathrm{E}-14$ & Olfactory receptor 5P3 \\
\hline gi|734651298 & 2.235869226 & $1.12 \mathrm{E}-13$ & Olfactory receptor 4D2 \\
\hline gi|734620673 & 3.143453592 & $4.55 \mathrm{E}-13$ & Olfactory receptor 11H6 \\
\hline gi|734633862 & 6.38787232 & $4.67 \mathrm{E}-12$ & Olfactomedin-like protein 3A \\
\hline gi|734643368 & 3.898067052 & $1.74 \mathrm{E}-11$ & Olfactory receptor 2D3 \\
\hline gi|326909552 & 2.628880419 & $2.90 \mathrm{E}-11$ & Olfactory receptor 52K1 \\
\hline gi|734643370 & 5.250368796 & $3.62 \mathrm{E}-11$ & Olfactory receptor 2D3 \\
\hline gi|734637571 & 2.606512606 & $4.88 \mathrm{E}-11$ & Olfactory receptor 2A12 \\
\hline
\end{tabular}

Table 4: Significant expressed olfactory receptor related genes by L-Tryptophan.

\begin{tabular}{|c|c|c|c|}
\hline Gene ID & Log $_{2}$ Fold Change & Padj-value & Gene description \\
\hline gil734901234 & 3.37537024 & $1.95 \mathrm{E}-26$ & $\begin{array}{c}\text { Trace amine associated } \\
\text { receptor3 }\end{array}$ \\
\hline gil734214493 & 2.15030369 & $1.00 \mathrm{E}-12$ & $\begin{array}{c}\text { Trace amine-associated } \\
\text { receptor } 13 \mathrm{c}\end{array}$ \\
\hline gi|734991831 & 1.11043545 & 5.09E-05 & Olfactory receptor 52E4 \\
\hline gi|734649654 & -2.28188197 & $1.94 \mathrm{E}-20$ & $\begin{array}{c}\text { Trace amine-associated } \\
\text { receptor } 4\end{array}$ \\
\hline gi|534620643 & -4.866844474 & 0.00018405 & $\begin{array}{l}\text { Trace amine-associated } \\
\text { receptor } 1\end{array}$ \\
\hline gi|52317194 & 3.940510448 & 0.00019588 & Olfactory receptor 2D3 \\
\hline gi|734621990 & 2.040046122 & 0.000240667 & Olfactory receptor 52D1 \\
\hline gi|734620311 & 1.081866298 & 0.000276195 & $\begin{array}{c}\text { Trace amine-associated } \\
\text { receptor } 1\end{array}$ \\
\hline gi|734625883 & 1.319022072 & 0.00038758 & Olfactory receptor $52 \mathrm{E} 4$ \\
\hline gi|7346201992 & 2.677476043 & 0.000414073 & Olfactory receptor 2D3 \\
\hline gi|734624112 & 1.662976473 & 0.000753161 & Olfactory receptor $2 \mathrm{~A} 12$ \\
\hline gi|7346203390 & 1.74786537 & 0.001249649 & Olfactory receptor $51 \mathrm{E} 1$ \\
\hline gi|7346204590 & 1.01851296 & 0.002207671 & Olfactory receptor 15 \\
\hline gi|346206734 & 2.11043545 & 0.003044982 & Olfactory receptor $52 \mathrm{~K} 1$ \\
\hline gi|326909507 & -1.188772569 & 0.004981766 & Olfactory receptor $13 \mathrm{C} 2$ \\
\hline gi|326909561 & -1.51892117 & 0.006838814 & Olfactory receptor 52N5 \\
\hline 4629832 & 3.525472949 & 88 & $\begin{array}{c}\text { Trace amine-associated } \\
\text { receptor } 13 \mathrm{c}\end{array}$ \\
\hline gi|734620673 & 1.303080528 & $5.16 \mathrm{E}-08$ & Olfactory receptor $11 \mathrm{H} 6$ \\
\hline gi|499004176| & -1.644452052 & 0.026442921 & Olfactory receptor $10 \mathrm{~A} 7$ \\
\hline gi|554883882 & 2.525472949 & 0.037969313 & $\begin{array}{l}\text { Olfactomedin-like } \\
\text { protein } 2 \mathrm{~B}\end{array}$ \\
\hline
\end{tabular}

Table 5: Significant expressed olfactory receptor related genes by L-Arginine.

\begin{tabular}{|c|c|c|c|c|c|c|}
\hline $\begin{array}{c}\text { Groups- } \\
\text { control }\end{array}$ & Up-gene & Down-gene & OR & VR & TAAR & OLFM \\
\hline L-Tryptophan & 11612 & 7162 & 56 & 1 & 16 & 10 \\
\hline L-Arginine & 15315 & 4100 & 55 & 1 & 19 & 12 \\
\hline
\end{tabular}

Table 6: Number of DEGs of olfactory related genes induced by pure L-amino acid.

\begin{tabular}{|c|c|c|c|c|}
\hline \multirow{2}{*}{$\begin{array}{c}\text { Gene } \\
\text { Types }\end{array}$} & \multicolumn{2}{|c|}{ Tryptophan } & \multicolumn{2}{c|}{ Arginine } \\
\cline { 2 - 5 } & Up-regulated & Down-regulated & Up-Regulated & Down- Regulated \\
\hline OR & 33 & 23 & 52 & 3 \\
\hline VR & 1 & 0 & 1 & 0 \\
\hline TAAR & 10 & 6 & 17 & 2 \\
\hline OLFM & 6 & 4 & 9 & 3 \\
\hline
\end{tabular}

Table 7: Number of up and down regulated olfactory related genes induced by pure L-amino acid.

is clearly seen that there is an increase in the number of Up genes than the Down genes for both L-Arginine and L-Tryptophan as opposed to non-expressed genes (Figure 11).

\section{Analysis of differentially expressed genes (DEGs) and identi- fication of olfactory related genes}

According to the criteria $\left(\mid \log _{2}\right.$ Ratio $\mid \geq 1$ and FDR $\left.<0.001\right)$, a total of 16701 differentially expressed genes were detected, including 10142 up-regulated and 6503 down-regulate.

A total of 111 olfactory receptor genes (OR genes) were detected. 56 OR genes from L-Tryptophan which included 33 up-regulated and 23 down-regulate, 55 olfactory receptor genes were detected from L-Arginine which include 52 up regulated and 3 down regulated genes (Tables 4 and 5); 1 up-regulated vomeronasal receptor genes (VR genes) was identified with no down-regulated genes for L-Tryptophan and for L-Arginine, 1 up-regulated VR genes with no down regulated gene was identified; 19 trace-amine associated receptor genes (TAAR genes) including 10 up-regulated and 6 down-regulated for L-Tryptophan and 17 up-regulated and 2 down-regulated were identified for L-Arginine; 10 olfactomedin like protein (OLFM) was identified for L-Tryptophan with 6 up-regulated and 4-down regulated genes where as 12 OLFM was identified for L-Arginine with 9 up-regulated and 3 downregulated genes. Thus, $O R$ gene group was dominant within the four different kinds of olfactory related receptor genes and were mainly activated genes by L-Tryptophan and L-Arginine (Table 6).

From the 111 differentially expressed $O R$ genes, 72 unigenes were identified as significantly expressed genes following the criteria $\left(\log _{2}\right.$ Ratio $\left.>2\right)$. With reference to the RPKM value of L-tryptophan and L-arginine $>1$ as $100 \%$ and RPKM of S-control $<10 \%$ for those 72 significantly expressed genes (Table 7), 9 OR genes were selected for Real-time qPCR.

Gene ontology (GO) analysis of DEGs: To determine the function of differentially expressed genes, all of the DEGs in this study were mapped to terms in the GO database. A total of 16701 genes were categorized into the three main categories of GO classifications, which is biological processes, cellular components, and molecular functions.

Following Gene Ontology, 16701 differentially expressed genes were categorized (10142 up-regulated and 6503 down-regulated genes) under the following; biological processes cellular process singleorganism process and biological regulations. The most represented cellular component was cell part (GO:0044464, 82.5\% up, 77.0\% down) followed by catalytic activity (GO:0003824, 55.1\% up, 48.0\% down) Molecular functions was represented by binding (GO: 0005488, $57.2 \%$ up, $53.9 \%$ down) followed by catalytic activity (GO:0003824 $32.6 \%$ up, $27.2 \%$ down). 
Citation: Franklyn A, Wang Y, Yu N, Wang J, Le Q, et al. (2017) Transcriptome Analysis Reveals L-amino Acids as Olfactory Stimulant in the Large Yellow Croaker (Larimichthys crocea). J Aquac Res Development 8: 475. doi: 10.4172/2155-9546.1000475

For olfactory reaction, four categories (GO. No, p-value) played important, which including signaling (GO:0023052, 1.1E-27), single organism signaling (GO:0044700, 1.1E-27), cell communication (GO:0007154, 4.6E-29) and signal transduction (GO:0007165, 1.3E-22 ). These categories are highly enriched and all relative to the nerve signal and they are transformed from odor molecules by olfactory system and then transmitted to the brain. And 72 genes were involved in olfactory receptor activities (GO:0004984) for molecular functions (Figure 12).

\section{RPKM (Reads Per Kilobase per Million mapped reads)}

RPKM was used to understand the number of gene expression; the greater the number of genes, the more active the genes. RPKM differential gene expression may not be significant. A single compound group such as gi|73461592 with a high RPKM but with a $\log 2$ FoldChange value is only 2.07 , the control groups set study of the gene differential expression are in connection with changes in the environmental conditions (Figure 13). However, RPKM values can be differentially expressed genes between reactions, these changes are brought about by time as well as the experimental conditions. All these changes reflect the gene expression process.

RPKM of Vomeronsal receptor (VR) stimulated by four genes: The olfactory neuron of Large yellow croaker is induced by two L-amino acids (L-Arginine and L-Tryptophan). Based on the Figure 14 , vomeronsal receptor (VR) were stimulated by L-amino acid with a significant difference in expression with gi|734616092 showing an upward trend, but no expression of gi|73464892 (Figure 14).

RPKM of OLFM stimulated by two compounds: OLFM is part of the olfactory protein. It functions mainly as an olfactory signaling

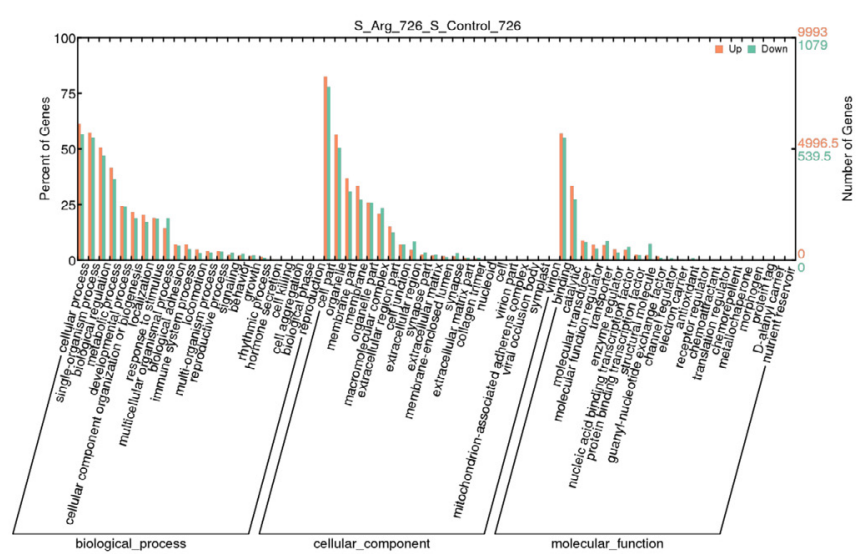

Figure 12: GO Function Enrichment analysis of DEGs.

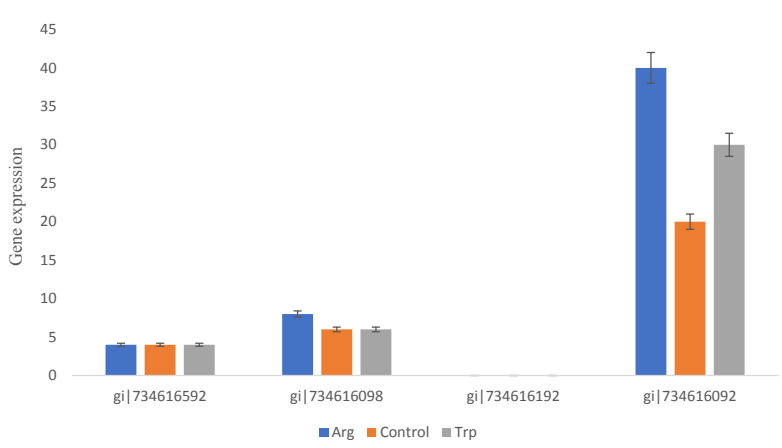

Figure 13: Value of RPKM of VR stimulated by four genes.

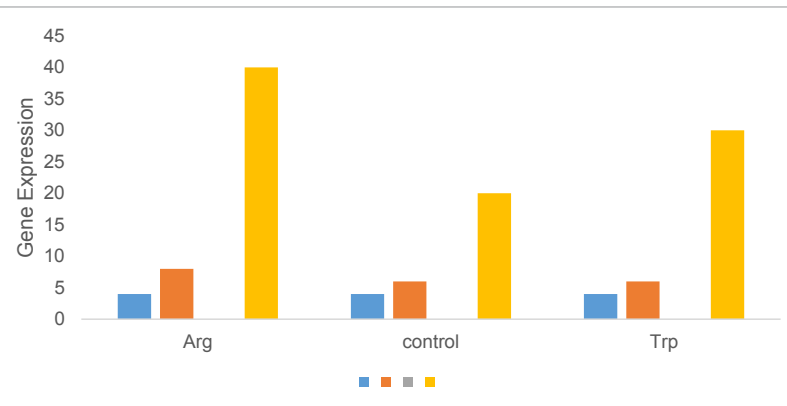

Figure 14: Value of RPKM of VR stimulated by four genes.

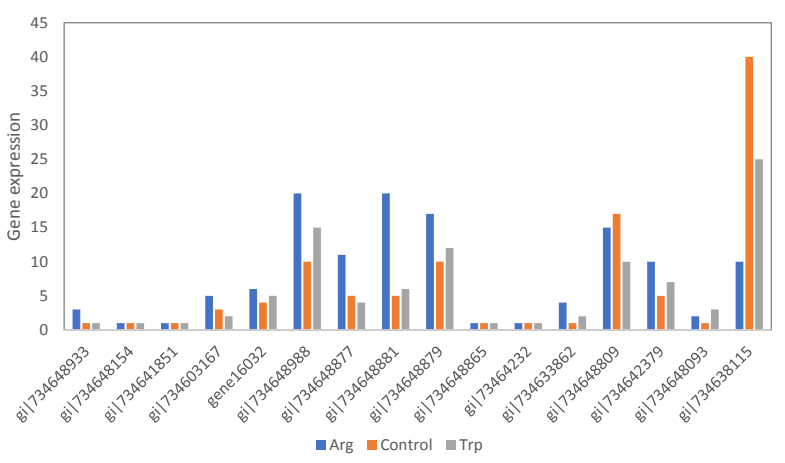

Figure 15: The RKPM value of OLFM stimulated by two compounds.

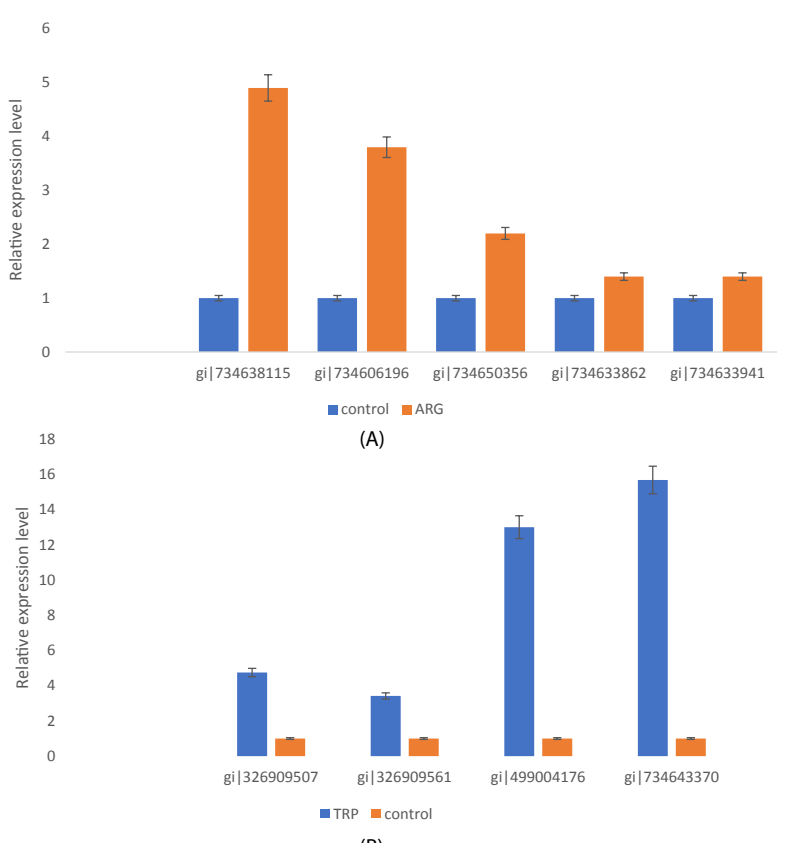

(B)

Figure 16: (16A) Real-time quantitative PCR (qRT-PCR) result of 5 differentially expressed olfactory receptor genes from L-Arginine (16B) Real-time quantitative PCR (qRT-PCR) result of 4 differentially expressed olfactory receptor genes from L-Tryptophan.

transmembrane component or as a signal binding factor. Data obtained from $\log _{2}$ FoldChange $>2$, padj $<0.05$ expression and significant of all related genes. These include gi|734638115, gi|734648881, with a maximum $\log _{2}$ FoldChange of $5.46 \%$, while in Figure 15 , its clearly seen that gi|734648877 is high but its $\log _{2}$ FoldChange is 2.99 . 


\section{Quantitative Real-Time PCR analysis}

RT-qPCR analysis was carried out on 9 expressed genes. 4 expressed genes stimulated by L-Arginine (Figure 16A) and 5 expressed genes stimulated by L- tryptophan (Figure 16B). Relative expression levels were calculated based on $2^{-\triangle \Delta C T}$ using beta actin as internal reference gene $(p<0.05$ and $p<0.01)$. The expression levels of 9 different olfactory receptor genes selected from the transcriptome data in line with the RT-qPCR result. This further corroborates the gene sequence data and expression.

\section{Discussion}

\section{Mode of Feeding of Psuedoscianea crocea}

The prime means of feeding in fish is by smell, in order to ensure a good experiment, we need to eliminate any environmental factors which can hinder the efficient breeding of the fish during the experiment. One of which was the white spot disease (Ichthyophthirius multifilis) which is caused by a protozoan. It damages the skin and gills causing the fish not to eat and consequent death this was dealt with by administering a treatment of formaldehyde. Also, introducing the fish into a new environment (from the sea to the ponds) the fish were given three weeks to adapt to their new environment before the experiment was conducted. A suitable fish density of $90 / \mathrm{m}^{3}$ was used with an optimum water temperature of $20^{\circ} \mathrm{C}$ with continuous input of fresh sea water twice a day and a constant aeration of the pond.

Role of smell in feeding: Like other bony fish, feeding preference in the large yellow croaker is determined by the smell and taste of the food. It has been proven that the large yellow croaker possesses a perfect and developed olfactory system [13]. The feeding is mainly controlled by the olfactory system, during this experiment, environmental conditions and light hinders the normal feeding of the fish, but it was found out that smell is the major cause of feeding but not the determining factor. From the control group, it can be deduced that to an extent not only smell can result in feeding in the fish but also the adaptation of the fish to their new environment. As the fish were also drawn towards normal feed but at a much slower rate than that with L-amino acids. The olfactory system differentiates the capacity of the odor due to individual differences. In this study, respond rate of large yellow croaker to L-Tryptophan, L-Methionine and L-Arginine was higher than the other seven L-amino acids.

Effect of different amino acid on the sensory organ of the large yellow croaker: Based at the experimental results, effect of L-amino acids (L-Arginine, L-Methionine, and L-Tryptophan) to large yellow croaker had high responsive rate, this indicates that L-amino acid is essential for the growth of the large yellow croaker. L-Tryptophan belongs to the non-polar aromatic amino acid, it is not only involved in the protein component of the fish but also in metabolism [14] and it is also found in fish meal. L-lysine is a major amino acid found in the food of fish but it shows no olfactory response in the fish. Hence with water soluble amino acid, they don't play any major role in the olfactory response to the fish but in nutrients metabolism which helps in the growth of the fish.

Morphological changes of the olfactory organ caused by L-amino acid: The olfactory system of fish can produce physiological and anatomical changes in specific environment. In this study, the morphological changes of the nerve cells under the effect of L-amino acid was studied and the relationship between the dilated and position of the epithelial cells was observed. The changes in these structural features were presumed that the odor of L-amino acid stimulates the expression of proteins in cilia nerve cells and a number of genes in a short period of time and thereby causing an inflation of the cilia nerve cells.

\section{Gene expression}

Olfactory receptor gene family in fish can be divided into 4 classes being; Olfactory Receptors (OR), Vomeronasal Receptors (VR), Trace-Amine Associated Receptors (TAAR) and FPR (formyl peptide receptors) which is mostly found in mice and now been reported in fish [15]. Results from gene cloning and sequencing of the large yellow croaker olfactory neurons shows the expression of OR, VR and TAAR genes with the exception of FPR. Three olfactory receptor genes were also expressed in the olfactory epithelium which functions in receiving of chemical information as fish lives in water. Olfactory perception in fish is through receptor genes which are three kinds; OR genes which target amino acid, bile salts, alcohols (found in food) and environmental information; VR genes which mostly target hormone function and TAAR genes which target the smell expression of the fish $[16,17]$.

Differentiation of Olfactory gene families in the large yellow croaker: The olfactory receptor gene family is divided into type 1 and type 2. It has nine categories with each type having sub types. The sub types can be divided into 4 isoforms. The sub type may not be expressed in the olfactory epithelium and olfactory receptor genes. The large yellow croaker has 100 OR receptor genes. The VR receptor family is divided into type I and II. Type I is divided into 6 families similar to zebra fish. The TAAR gene family can be divided into 3 categories namely type I, II and III.

Functional differentiation of olfactory receptor gene family: Bony fish have three main smell receptor gene of different functional expression [18]. The VR receptor genes are found in the olfactory epithelium of the microvilli. Functional difference is caused by changes in the external environment which are genetically intrinsic incentives.

Function of olfactory receptor protein: The large yellow croaker has three types of olfactory receptor protein which are g protein couple receptor types, all the receptors are similar. There are seven long 18-28 amino acid hydrophobic regions, $7 \alpha$-helical transmembrane protein (TM) which forms the domain, with a total length of about 300-350 amino acid [9]. But there are variations in the amino acids such as $\mathrm{N}$-terminal amino acid chains are at the extracellular side, T-terminal inside the membrane, which forms three rings on each side of the cell membrane. TM OR gene region consists of three intracellular loops (IC) and 3 extracellular loops (EC), with the large yellow croaker, OR, VR and TAAR gene are different from olfactory receptor protein, odor receptors respond to external environment are also different and the sensitive perception of materials are also different.

Olfactory receptor-ligand recognition mechanisms: Based on the study of single olfactory neuron, it was found out that 1 olfactory neuron expresses only 1 OR gene family [19]. Single OR receptors can recognize various odors and an odor can also be recognized by multiply OR genes; but recognition of different odors can be a combination of different olfactory receptors, which makes the research of smell and ligand binding complicated. The olfactory receptor family identify odor molecules through a combination of receptor genes.

\section{Conclusion}

As one of the major marine food in China, the cultivation of the large yellow croaker has decrease drastically within the past years [20] 
Citation: Franklyn A, Wang Y, Yu N, Wang J, Le Q, et al. (2017) Transcriptome Analysis Reveals L-amino Acids as Olfactory Stimulant in the Large Yellow Croaker (Larimichthys crocea). J Aquac Res Development 8: 475. doi: 10.4172/2155-9546.1000475

this study select appropriate L-type amino acid as feed stimulant for Larimichythys crocea with a comprehensive transcriptome analysis of the olfactory epithelium stimulated by amino acid. Comparing the olfactory organ before and after the administering of L-amino acid shows stimulation of the olfactory epithelium as the apex of the ciliary structure was inflated, presumable that a specific receptor protein is associated with a short time activation. Many olfactory genes were identified which were stimulated by amino acid. It also responsible for other olfactory activities such as signaling, single organism signaling, cell communication and olfactory transduction. These data support the phagostimulant effect of l-amino acid and provide valuable information relating to gene expression and the olfactory system of Larimichythys crocea.

\section{Acknowledgments}

We thank shunshun tao of xianshang habor larval rearing corporation and Dr. Bao of Wanli college of zhejing. This study was partially funded by Zhejian provincial natural science foundtation (LY15C190003), The Key Special Project of Ningbo City (China) in Agriculture (2015C110003), Collaborative Innovation Center for Zhejiang Marine High-Efficiency. Finally, it was also supported by K.C. Wong Magna Fund in Ningbo University. We would like to thank the native English speaking scientists of Elixigen Company (Huntington Beach, California) for editing our manuscript.

\section{References}

1. Hara TJ (1994) Olfaction and gustation in fish: An overview. Acta Physiological Scandinavica 152: 7-17.

2. Kortschal K (1995) Ecomorphology of solitary chemosensory cell system in fish: A review. Environ Biol Fish 44: 10-13.

3. Hassenklover T, Pallesen LP, Schild D, Manzini I (2012) Amino acid- vs. Peptide Odorant response of individual olfactory receptor neurons in an aquatic species, PLoS ONE7 12: 9-13.

4. John C (1975) High sensitivity of catfish taste receptors to amino acids. Comp Biochem Physiol 52A: 247-251.

5. Idler DE, McBride (1961) Olfactory perception in migrating salmon: II. Studies on a laboratory Bio-Assay for Homes stream water and mammalian repellent. Can J Biochem Physiol 39: 1575-1584.

6. John TC (1997) Olfaction and taste in the channel catfish:An electrophysiological study of the responses to amino acids and derivatives. J Comp Physiol 123: 357-371.
7. Freitag J, Ludwig GAI, Rosseler P, Breer H (1998) Olfactory receptors in aquatic and terrestrial vertebrates. J Comp Physiol A p: 35-50.

8. Gloriam D, Tkyan B, Yi-Lin Y, John HP, Helgi BS, et al. (2005) The repertoire of trace amine G-protein-couple receptors: large expansion in Zebra fish. Molecular phylogenetic and Evolution 35: 70-82.

9. Isabelle G, Rouquir S, Chavanieu A, Mollard P, Giorgi D (2004) Amino acid changes acquired during evolution by olfactory receptor modifies the specificity of odorant recognition. Human Molecular genetics 13: 771-780.

10. Rolen SH, Sorensen PW, Mattson D, Caprio J (2003) Polyamines as olfactory stimuli in the gold fish Carassius auratus. J Expt Biology p: 83-96.

11. Tetsuya K, Nobuhiko M, Kozo M, Kazuhide A, Akihiro U, et al. (2009) Olfactory neural circuitry for attraction to amino acids revealed by transposon-mediated gene trap approach in zebra fish. Proceedings of the National Academy of Sciences of the United States of America p: 84-89.

12. Cole T, Lior P, Steven LS (2009) TopHat: discovering splice junctions with RNAseq. Bioinformatics p: 1105-1111.

13. Anne H, Shane HR, Aderson K, Morita Y, Caprio J, et al. (2003) Correlation between olfactory receptor cell type and function in the channel catfish. $J$ Neurosci 23: 9328-9339.

14. Mac LP (1971) Structure and function of higher olfactory centers. Sens Physio p: $182-204$.

15. Glusman G, Anita B, Dror S, Yitzhak P, Julia W, et al. (2000) The olfactory receptor gene superfamily: Data mining, classification and nomenclature Mamm Genome p: 16-23.

16. Hayden S, Michael B, Tess AC, Stefano M, William JM, et al. (2009) Ecologica adaptation determines functional mammalian olfactory sub genomes. Genome Research p: 1-9.

17. Borowsky B, Adham N, Jones KA, Raddatz R, Artymyshyn R, et al. (2001) Trace amines: Identification of a family of mammalian G-protein- coupled receptors. Proceedings of the National Academy of Science of the United States of America 98: 8966-8971.

18. Gonzalez A, Ruth M, Jesus ML, Nerea M, Glenn RN (2010) Lungfishes, like tetrapods, possess a vomeronasal system. Frontiers in Neuroanatomy 4: 130.

19. Shannon DM, Ngai J (2010) The cell biology of smell. J Cell Biology p: 43-52.

20. Lui M, De Mitcheson YS (2008) Profile of a fish collapse: Why Mariculture failed to save the large yellow croaker (Larimichthys crocea). Fish and Fisheries 9 219-242. 